\title{
Entre el miedo y el derecho al delirio: un decir desde los ninguneados de Eduardo Galeano*
}

\author{
Carlos Alberto Chacón Ramírez** \\ Diego Alejandro Botero Herrera***
}

Recibido: 14 de agosto de 2015 Evaluado: 11 de septiembre de 2015 Aceptado: 30 de septiembre de 2015

\section{ReSUMEN}

Este artículo presenta una reflexión desde un recorrido lector y escritural de la obra del escritor uruguayo Eduardo Galeano (1940-2015), en la cual los ninguneados como personajes de creación literaria son la fuente que anuncia las condiciones de la vida moderna con sus signos de desigualdad y miedo. Pero también, en condición sensible de posibilidad, el derecho al delirio como abandono y resistencia a las marcas infligidas por los discursos y actos omniabarcantes y totalitarios, resultado de la crisis de civilización a la que asistimos.

El artículo dice de Eduardo Galeano, como hombre de letras y palabras, que subvierte las maneras inefables del poder, para hacer y pronunciar desde ellas las resistencias a sus fuerzas homogeneizantes. Este autor delira y construye las figuras del

\footnotetext{
Artículo de reflexión. Es un avance de la investigación monográfica Lo auroral y el ocaso: una metáfora geo-atmosférica para pensar las tensiones y crisis entre la naturaleza y las culturas, que hace parte del trabajo académico y de grado en el Grupo de Investigación en Biodiversidad y Educación Ambiental de la Universidad del Quindio (BIOEDUQ) (Colombia). Cómo citar este artículo: Chacón Ramírez, C.A., y Botero Herrera, D.A. (2016). Entre el miedo y el derecho al delirio: un decir desde los ninguneados de Eduardo Galeano. Hallazgos, 13(25), 19-40 (doi: http://dx.doi.org/10.15332/ s1794-3841.2016.0025.01).

* Licenciado en Educación, Área Mayor Biología, de la Universidad del Quindio (Colombia); especialista en Educación Ambiental de la misma universidad y en Gerencia Ambiental, de la Universidad Santiago de Cali (Colombia); magíster en Educación de la Universidad Santiago de Cali; doctor en Educación, de la Universidad del Valle; postdoctorante en Ciencias Sociales, Niñez y Juventud, de la Universidad de Manizales (Cinde). Docente de planta del programa Académico Licenciatura en Biología y Educación Ambiental de la Universidad del Quindío. Correo electrónico: carloschacon@ uniquindio.edu.co

*.* Técnico profesional en Gestión de Recursos Naturales; aspirante a Licenciado en Biología y Educación Ambiental de la Universidad del Quindío (Colombia). Correo electrónico: daboteroh@uqvirtual.edu.co
} 
ninguneado, los nadies, los ningunos, como cuerpos de la periferia, excluidos por las maneras biopolíticas de controlar el mundo.

Figuras que se presentan como sarcasmos poéticos para pensar el desarrollo, la explotación bárbara de la vida humana y no humana, el desgarramiento de una tierra ya no habitada sino dominada y el sufrimiento humano como efecto devastador de sus designios.

El ensayo contiene rasgos biográficos en cuanto vida y obra del escritor uruguayo, apuntes etimológicos y secciones narrativas en torno a la condición de los nadies como cuerpos del exilio en la morada habitada; así mismo, de manera crítica, el desarrollo como promesa sobre el temor de los ninguneados, y finaliza con un fragmento del derecho al delirio: sentida muestra de su pensamiento.

Palabras clave: derecho al delirio, desigualdad y miedo, los ninguneados, cuerpos del exilio, los dueños de nada. 


\section{Between fear and the right to delirium: a perspective from the neglected in Eduardo Galeano's work}

\author{
Received: August 14, 2015 \\ Evaluated: September 11, 2015 \\ Accepted: September 30, 2015
}

\section{Abstract}

This article presents a refection upon a reader and writer's itinerary of part of Uruguayan writer Eduardo Galeano (1940-2015), where the neglected as characters of literary creation are the source which announces the living conditions of modern life with its signs of inequality and fear. But also, in a sensitive condition of possibility, the right to delirium as abandonment and resistance to the wounds inflicted by the discourses and omnipresent and totalitarian acts, result of the civilizing crisis which we attend.

This article describes Eduardo Galeano as a man of literature and words which subvert the ineffable ways of power in order to do and state from them resistance to homogenizing forces. An author who is delirious and constructs the figures of: the neglected, the nobodies, the no-ones, as bodies of the periphery, excluded by the bio-political ways of controlling the world. Figures as poetic sarcasm to think about the development, the barbaric exploitation of human and non-human life, the upheaval of a land which is no longer inhabited but dominated, the human suffering as a devastating event of its own designs.

It contains biographic features both about the Uruguayan writer's life and his writings, etymological notes and narrative sections about the condition of the neglected as bodies in exile in the inhabited dwelling; as well, as a way of critique, the development as a promise about the fear felt by the neglected; and finalizes with a fragment of the book the right to delirium: a heartfelt sample of his thinking.

Keywords: Right to delirium, inequality and fear, the neglected, bodies in exile, the owners of nothing. 


\section{Entre o medo e o direito ao delírio: um relato a partir dos "niguéns" de Eduardo Galeano}

\section{RESUMO}

Este artigo apresenta uma reflexão muito cuidadosa da obra do escritor uruguaio Eduardo Galeano (1940 - 2015), na qual os "ninguéns", personagens de criação literária, são fonte que anunciam as más condições da vida moderna, com seus signos da desigualdade e medo. Mas também, em condição sensível de possibilidade, o direito ao delírio como resistência às marcas determinadas pelos discursos e atos centralizadores e totalitários, resultados da crise de civilização a qual participamos.

O artigo revela Eduardo Galeano como homem de letras e palavras, que as subverte de maneira indescritível para se pronunciar a partir da resistência mostrando as forças homogeneizantes do poder. Este autor delira e constrói as figuras dos "ninguéns", os invisíveis, ninguém, corpos da periferia, excluídos pela maneira política de controlar o mundo. Figuras apresentadas com sarcasmo poético para se pensar no desenvolvimento, na exploração bárbara da vida humana e não humana, no desgarramento de uma terra não habitada, mas dominada, e no sofrimento humano como o efeito devastador de seus sonhos.

O ensaio contém traços biográficos da vida e obra do escritor uruguaio, apontamentos etimológicos e seções narrativas em torno da condição dos "ninguéns", como corpos do exílio e o desenvolvimento como promessa que sobrescreve o temor dos "ninguéns", finalizando com um fragmento do direito ao delírio: a mostra mais forte de seu pensamento.

Palavras-chave: direito ao delírio, desigualdade e medo, "ninguéns", corpos do exílio, os donos de nada.

Recebido: 14 de agosto de 2015

Avaliado: 11 de setembro de 2015

Aceito: 30 de setembro de 2015 


\section{Obertura: APUNTES \\ BIOGRÁFICOS DE LA VIDA Y OBRA de Eduardo Galeano}

Eduardo Germán María Hughes Galeano, más conocido en el mundo de las letras como Eduardo Galeano, nació en Montevideo, República Oriental del Uruguay, un martes 3 de septiembre de 1940. Fue el primero de tres hermanos, hijos del matrimonio entre Eduardo Hughes Roosen y Ligia Esther Galeano Muñoz, y heredero de un linaje italiano, galés, español y alemán. Para entonces, Montevideo era un lugar aldeano y sin prisas, mientras el mundo se debatía en los debacles de la Segunda Guerra Mundial (Kovacic, 2015).

Eduardo Galeano, periodista y escritor, es considerado uno de los autores más brillantes e influyentes de la literatura latinoamericana. Tuvo una formación laica, pero su familia era fervientemente católica. A los nueve años quería ser santo, aunque años más tarde reconoció: "tuve una infancia muy mística, pero no me fue bien con la santidad". Muy joven abandonó sus estudios y se dedicó a trabajar en correspondencia a dos factores: el escaso apego al estudio como instrucción sistemática y el divorcio de sus padres en 1955. Su primer trabajo fue en una fábrica de insecticidas, donde hacía la distribución de los pedidos (Kovacic, 2015). A los catorce años, recién cumplidos, publicó por primera vez una caricatura política en el semanario El Sol, un medio socialista de la época. Firmaba los dibujos como "Gius", la pronunciación en castellano de Hughes, apellido paterno que se remonta a un tatarabuelo católico que huyó de Gales al Uruguay en el siglo xix. Hasta los dieciocho años alternó el dibujo con algunas crónicas de arte y de movimientos sindicales. En 1963 publicó su primer libro (una novela) titulado Los días siguientes que firmó como "Galeano", su apellido materno que viene de un tatarabuelo Genovés (Galeano, 1984). Desde entonces, siguió firmando sus obras de esta manera. A sus 17 años ya militaba en el partido Socialista de Uruguay, un defecto imperdonable para su familia. El acercamiento a este partido se produjo con la guía de su amigo Guillermo Chifflet, que escribía para el semanario El Sol, donde Galeano publicó sus primeros dibujos y notas. Durante esta época de militancia, su referente político fue Emilio Frugoni, primer legislador del socialismo uruguayo y defensor de los derechos civiles de la mujer. La influencia de la madre y la abuela en Galeano forjó una profunda marca de lo femenino como contrapeso a su lado varonil, que permaneció durante toda su vida y su obra. No en vano, en Días y noches de amor y de guerra, uno de sus libros más conocidos, Eduardo Galeano le dedica tres páginas a su abuela.

Por otro lado, el rechazo frente a la hipocresía, el rescate de la pasión y del sentimiento vivo, así como la importancia que le asigna a la palabra en cuanto relato de los hechos, son rasgos permanentes en la escritura de Galeano (Kovacic, 2015). Su sentido de pertenencia era inquebrantable; siempre tuvo muy presente que era latinoamericano. Aunque se reconocía en un crisol de etnias ancestrales originarias de Europa, su sangre era criolla por haber nacido en América del Sur (Kovacic, 2015). Él mismo decía: “Tatarabuelos de Gran Bretaña, España, Italia y Alemania; cara de cónsul sueco en Honduras. Y sin embargo, desde siempre supe que soy tan latinoamericano como las piedras de Machu Picchu" (Galeano, 1984, p.154). 
En Galeano primero fue la imagen y luego la palabra. En principio, quería ser pintor, pero se convirtió en un hombre que pintaba escribiendo, a falta, según él, de talento para pintar pintando. Sin más remedio, fue un autor para quien la historia está viva y actúa sobre el presente. No fortuitamente se preguntaba por las razones que justifican al mundo construido por el hombre moderno, en el que cada minuto se gastan millones de dólares en la industria béli$\mathrm{ca}$, mientras en ese mismo tiempo mueren aproximadamente, en la impunidad de los culpables, treinta niños por hambre o enfermedad. En este sentido, fue un autor que escribió con obsesión por la memoria, ante todo la de América Latina, tierra condenada a la amnesia que se ha traducido en desigualdad obligatoria. Su pluma, siempre estuvo alentada por preguntas como: “¿Qué tiempo pasado parió este tiempo presente? ¿Por qué unos países se han hecho dueños de otros países, y unos hombres dueños de otros hombres, y los hombres dueños de las mujeres [...] y las cosas dueñas de las personas?" (Galeano, 1984, p. 154). Eduardo Galeano sabía que los hechos del presente no tienen un origen inexplicable, sino que contienen la impronta de otros hechos del pasado, junto a la firma y el ADN de los seres humanos (Kovacic, 2015).

Eduardo Galeano fue un hombre uruguayo que se formó literariamente en los cafés de la Montevideo de la década de los cincuenta, lugar de pasatiempo de aquellos que llegaron a este país huyendo de la Guerra Civil Española; lugar de bohemios, obreros, prostitutas y tahúres, que en medio de acaloradas discusiones y noches de farra construían su trágica narrativa de la vida. Un bar de la época "era el espacio orillero que las luces de la gran ciudad guardaban a quienes dejaba fuera del festín de la modernidad con su espejismo de progreso hacia un futuro reservado a unos pocos" (Kovacic, 2015, p.16). Gracias a Carlos Onetti, a quien señaló muchas veces como su tutor literario, y a Paco Espínola, novelista, de quien recordaba sus historias, descubrió estos lugares de libertad donde la palabra vive, vivifica y se mueve sin censura. Galeano alguna vez confesó acerca de sus comienzos: "me crie escuchando a los viejos en las reuniones de café y esa oralidad fue fundamental en mi formación" (Kovacic, 2015, p. 15). La ignición de su espíritu rebelde y la búsqueda permanente de sentidos ocurrieron en estos cafés. Andadura en la que muchas veces evocó a José Artigas, héroe revolucionario de Uruguay: imagen elocuente de la resistencia criolla al sistema presidido por una élite segregativa aferrada al poder. En consecuencia, Eduardo Galeano, fue un "contador" de las historias de los vencidos, para que su voz y su memoria siempre fueran escuchadas (Galeano, 1984).

Antes de poder vivir del periodismo desempeñó otros oficios: fue mensajero, peón de fábrica, cobrador, taquígrafo, cadete y cajero de banco. Trabajó como editor y viajó por América Latina y el mundo. Su habilidad para las palabras le valió un puesto en la oficina de publicaciones de la Universidad de la República de Uruguay. El trabajo en el banco alternó con sus primeras experiencias periodísticas en $\mathrm{El}$ Sol, y le sirvió para confirmar, de acuerdo con la frivolidad de las oficinas bancarias, que no era lo que deseaba para su vida. Durante este tiempo nacieron sus primeras y deliberadas aventuras literarias. Entre 1960 y 1964, trabajó como colaborador y editor de la revista Marcha 
de la mano de su director, Carlos Quijano. Allí empezaron a aparecer los trazos de un periodismo crítico, desconfiado del poder y en rescate de los olvidados por el sistema, a los que llamaría ninguneados. Con 22 años, fue editor del diario Época. En 1963 viajó por China, la Unión Soviética y Checoslovaquia (Kovacic, 2015). En 1971, escribió su reconocida obra Las venas abiertas de América Latina, que cuenta con más de 30 ediciones y traducción a más de 20 idiomas. Allí demostró con rigurosidad periodística que la pobreza en América del Sur no es el fruto de una maldición o de la incapacidad de su pueblo, sino el resultado del desarrollo económico extranjero: España, Estados Unidos, Inglaterra, Francia, Holanda y Portugal.

En 1973, Galeano salió de Uruguay rumbo a Argentina y empezó su primera etapa del exilio. En ese entonces, dirigía en Buenos Aires la revista Crisis fundada por Federico Vogelius. Para 1976, figuraba en la lista de amenazados de muerte por la Alianza Anticomunista Argentina (Triple A). Así comenzó una segunda etapa en su camino como exiliado. En compañía de su esposa, Helena Villagra, partió rumbo a la Península Ibérica. Se instalaron en Calella de la Costa cerca de Barcelona. Ya en España publicó las dos primeras entregas de la trilogía Memoria del Fuego: en 1982, Los nacimientos y en 1984, Las caras y las máscaras. El exilio acabó en 1985, cuando regresó a su país al finalizar la dictadura cívico-militar uruguaya, al asumir la presidencia mediante elecciones democráticas Julio María Sanguinetti. En noviembre de 1986, llegó a las librerías el tercer tomo de la trilogía, El siglo del viento. En Uruguay, en compañía de Mario Benedetti y otros intelectuales, fundó el semanario Brecha, retomando el tono crítico de Marcha. Tiempo después, abrió su propia editorial, El Chanchito, nombre que alude a la figura que usaba para firmar sus cartas.

Toda la obra del recordado escritor uruguayo traspasa sin ningún temor ni remordimientos las fronteras de los géneros literarios. En sus textos conviven y se funden la narrativa, la crónica periodística, el ensayo y la poesía. Su obra congrega la realidad y la memoria, la voz del alma y de la calle. Su escritura "sufre variaciones y va girando sobre sí misma [...] hasta desembocar en un cruce de géneros que van a parir un estilo propio equidistante de todo lo conocido, o mejor dicho construido con la argamasa de todo lo conocido" (Kovacic, 2015, p.103). Dentro de su vasta realización literaria se cuentan, entre otras, Los días siguientes (1963), Las venas abiertas de América Latina (1971), Vagamundo (1973), La canción de nosotros (1980), Días y noches de amor y de guerra (1978), la trilogía Memoria del fuego (1982-1986), El libro de los abrazos (1989), Nosotros decimos no (1989), Ser como ellos (1992), Las palabras andantes (1993), Úselo y tírelo (1994), El fútbol a sol y sombra (1995), Patas arriba: escuela del mundo al revés (1998), Bocas del tiempo (2004), Espejos (2008), Los hijos de los días (2011) y Mujeres (2015) (libro póstumo). Su creación se cuenta entre las más comprometidas políticamente del continente y contribuyó a la difusión del pensamiento social latinoamericano. Por su trabajo, fue elegido Primer Ciudadano Ilustre de los países del Mercosur, y recibió diversos reconocimientos como el premio José María Arguedas de la Casa de las Américas en Cuba (1975 y 1978) y el American Book Award (1989), de la Universidad de Washington (Navarrete, 18 de abril de 2015). En 2013, recibió en Chile el premio N'aitun de la Corporación Cultural 
de Artistas Proecología, que distingue a quienes colaboran con la defensa del medio ambiente (Kovacic, 2015).

Su literatura también ha sido motivo de duras críticas; una de las más severas la recibió por parte de Carlos Alberto Montaner, Plinio Apuleyo Mendoza y Álvaro Vargas Llosa, autores del libro Manual del perfecto idiota latinoamericano (1996), y con prólogo de Mario Vargas Llosa, premio Nobel de literatura y excompañero de Galeano en la revista Marcha. Los autores le dedican el tercer capítulo de su escrito a Las venas abiertas de América Latina, con el título "La biblia del idiota", donde se dedican a analizar con ironía algunos párrafos (Kovacic, 2015). En este manual, dice textualmente: “[...] biblia en la que se recogen casi todas las tonterías que circulan en la atmósfera cultural de eso a lo que los brasileros llaman 'la izquierda festiva' [...] pintoresca obra ayuna de orden, concierto y sentido común" (Apuleyo, Montaner y Vargas, 1996, p.31). En una entrevista de 2015 publicada por el diario en línea Emol, Mario Vargas Llosa declaró: "mis ideas políticas son muy distintas a las de Galeano. Estábamos prácticamente en las antípodas [...] Creo que sus tesis sobre América Latina estaban completamente equivocadas" (s. p.).Y agrega el reconocido escritor peruano, refiriéndose a Las venas abiertas de América Latina: "presenta una descripción completamente caricatural, de un dogmatismo marxista que caricaturiza y falsea profundamente lo que es la realidad de América Latina" (s. p.). Curiosamente, años antes, en Ser como ellos y otros artículos, Eduardo Galeano escribió: “[...] el novelista peruano Mario Vargas Llosa explica que no hay más remedio que modernizar a los indios, aunque haya que sacrificar sus culturas para salvarlos del hambre y la miseria" (Galeano, 1992, p. 20).

Durante la II Bienal del Libro y la Lectura, realizada en Brasilia en abril de 2014, una declaración de Galeano acerca de su obra más difundida (Las venas abiertas de América Latina) levantó gran revuelo y una avalancha de críticas entre los medios y los detractores del autor. "No volvería a leer Las venas..., no sería capaz de hacerlo. Para mí, esa prosa de la izquierda tradicional es aburridísima [...] No me arrepiento de haberlo escrito, pero es una etapa que, para mí, está superada". De inmediato, las voces internacionales no se hicieron esperar. En su edición del 1 de mayo de 2014, el diario argentino Perfil publicó: "Eduardo Galeano mató a su obra más conocida: Las venas...". En junio de ese mismo año, El Espectador de Colombia, publicó en edición electrónica una nota con un artículo del New York Time firmado por Larry Rother, donde se consultaba a diferentes escritores y académicos sobre la magnitud de las palabras del autor uruguayo en Brasilia. Por aquel tiempo, Carlos Alberto Montaner, cubano liberal, desde su página web tituló: "Galeano rectifica y los idiotas pierden su biblia", y luego: "Galeano se retractó del contenido del libro". Incluso el reconocido artista panameño, Rubén Blades, se sumó a esta oleada. En su blog del 19 de mayo de 2014, escribió: "Me gustaría aplaudir la honestidad y madurez mostrada por Eduardo Galeano [...] La izquierda doctrinaria latinoamericana no ha podido trascender los desacreditados discursos de barricada, los apoyos incondicionales, la repetición de pensamientos invalidados por el tiempo" (Kovacic, 2015, p. 189). Valga señalar que Eduardo Galeano "nunca habló de arrepentimiento por haber 
escrito Las venas... sino de 'etapa superada'. 'No lo leería', sostuvo, lo cual es distinto que decir 'no lo volvería a escribir' (Kovacic, 2015, p. 189).

Así, no querido por algunos, pero aclamado por la mayoría, es reconocido por su aporte a la literatura latinoamericana y a la consolidación de un pensamiento Sur, no solo desde el punto de vista geográfico austral, sino como lugar del símbolo; entendiendo por "sur" la metáfora del sufrimiento padecido por el ser humano bajo el sistema capitalista globalizado (Santos, 2006). Finalmente, falleció en la Montevideo de sus amores en la mañana del 13 de abril de 2015 a los 74 años de edad. Desde una semana antes se encontraba muy delicado de salud por causa de un cáncer de pulmón que lo aquejaba hace algunos años. En 2007, le habían detectado un nódulo cancerígeno en su pulmón derecho y fue operado con urgencia en Montevideo. Aunque esta intervención fue exitosa, viajó a Cataluña para iniciar un tratamiento de quimioterapia, para prevenir futuras y graves consecuencias. Su salud quedó debilitada, pero este no fue un impedimento para continuar con su obra, participar en eventos académicos y culturales, y sobre todo viajar, una de sus pasiones. Ahora, su legado de palabras recorre los otrora caminos que él anduvo para mantener viva la memoria vencida de América Latina. Sus maneras de decir serán siempre la voz porfiada provocada por el río Uruguay; "río de los pájaros pintados", que según su significado en lengua guaraní, le sirvió de metáfora para trazar y colorear su mundo de libertad (Kovacic, 2015).

\section{ENTRE EL MIEDO, EL DERECHO Y EL DELIRIO: UNA TRIADA PARA PENSAR LOS NADIES}

La Real Academia Española (2014) indica que miedo como palabra derivada del latín metus $^{1}$, significa "perturbación angustiosa de ánimo por un riesgo o daño real o imaginario [...] recelo o aprensión que alguien tiene de que le suceda algo contrario a lo que desea $[. . .]^{\prime \prime}$. Su origen latino metus también alude a "[...] temor, inquietud, ansiedad, pavor [...] miedo a los enemigos [...] el temor a la muerte [...] temor al pretor [...], temor religioso" (Segura, 2014, p.374). Metus, además, es una "alegoría romana que representaba el temor y que acompañaba a Marte en los campos de Batalla" (Sechi, 2007, p.180). Pero no aparecía como un personaje real, era más una sensación abstracta. Esto lo hace cercano al miedo desplegado en el mundo moderno por las relaciones de poder, de influencia dramática sobre la vida.

Metus es el paralelo romano de Deimos, "uno de los cinco hijos de Ares y de Afrodita, cuyo nombre significa espanto" (Sechi, 2007, p.72). Deimos y su hermano Fobos eran los caballos que acompañaban a Ares en combate. En la Ilíada de Homero, "Ares invoca a Fobos [...] y a Deimos [...], personificaciones del terror y el horror respectivamente" (Rojas, 2015, p.162). Metus y su par griego Deimos representan, en cualquier caso, el horror de la guerra, por su vínculo con Marte y Ares, deidades equivalentes entre griegos y romanos. Como símbolos míticos, entrañan la realidad bélica de los

1 Cuando se escribe Metus con mayúscula se hace referencia al símbolo mitológico romano, en tanto metus, con minúscula, se refiere a la palabra del latín que dio origen a la voz castellana miedo. 
tiempos modernos que imponen la violencia que consigo arrastran.

Por otro lado, Alessandri, Somarriva y Vodanovic (1998) mencionan que la palabra castellana derecho, en su significado jurídico, aparece en escritos antiguos de principios del siglo xI de la era actual. Según el diccionario de la Real Academia Española (2014), derecho se deriva del latín directus y traduce lo siguiente: "recto, igual, seguido, sin torcerse a un lado ni a otro". El diccionario también señala: "facultad del ser humano para hacer legítimamente lo que conduce a los fines de su vida [...] justicia, razón [...] sendero, camino". Además, la academia alude a un coloquialismo para esta palabra: "[...] actitud de protesta que adopta o puede adoptar el que se siente defraudado en sus derechos". La significación jurídica del derecho está ligada etimológicamente al latín ius: "El sustantivo latino ius y que algunos escriben $j u s$, ha dado origen a justo, juzgar, jurídico y sus derivados" (Alessandri, Somarriva y Vodanovic, 1998, p. 14). En relación con esto, Suárez (2005) señala que "Derecho (ius) tiene varios sentidos, y uno de ellos es ley, esto es normatividad[...], iusa parece ligado a iustitia (justicia), en realidad aquello que es justo y equitativo[...]; equidad que a cada uno se le debe en justicia" (pp.47-48).

De esta tríada, el delirio, según su origen etimológico, trasciende las barreras impuestas por la definición psicológica enunciada por la Real Academia Española (2014): “confusión mental caracterizada por alucinaciones, reiteración de pensamientos absurdos e incoherentes". Delirio no se traduce únicamente en disparates y despropósitos, pues se deriva del latín delirium que, según
Monlau (1856) proviene "[...] del prefijo de que denota separación, y lirare, antiguo verbo que significa labrar un campo por rayas, hacer surcos[...] de-lirare por consiguiente es separarse del surco, desviarse [...], salirse del surco, de la recta razón" (p. 245). Esto convierte al delirio en sinónimo de resistencia al discurso omniabarcante del desarrollo y sus verdades obligatoriamente universales. El significado del "delirio ha establecido una tensión con el de la verdad" (Tornero, 2000, p. 27). Delirar no es demencia, como insiste la modernidad, sino que deviene en ruptura y encanto. " $\mathrm{Al}$ delirio inspirado por los dioses es al que somos deudores de los más grandes bienes [...] se precisa del delirio poético para despertar mediante los acentos musicales, las partes dormidas del alma" (Bordelois, 2006, p. 59). Por cuanto crítica y fuga a la organización colonial del mundo moderno, el delirio "[...] pone en cuestión a occidente como centro del mundo, y en esa medida, abre posibilidades para concepciones de modernidades alternativas" (Santos, 2006, p. 40).

\section{LOS NINGUNEADOS: CONDICIÓN DE LOS NADIES, LOS NINGUNOS, LOS DUEÑOS DE NADA}

Los ninguneados son la manera de Eduardo Galeano para nombrar a quienes él consideraba los innombrables: los muchos que son nada, los nadies. Hombres y mujeres sin voz, sin derecho a un destino, despojados de sus sueños y su memoria, bajo la estridencia de estos tiempos de hoy, que resuenan como el canto de sirenas que en la antigüedad agobió a Ulises, y que ahora los tecnócratas han bautizado: bienestar, desarrollo y progreso. Los nadies son el resultado de un 
orden mundial autocalificado como moderno, pero abrazado al antiguo "colonialismo [...], que ve al otro como objeto" (Santos, 2006, p.2); objeto del poder. Son ninguneados los millones de exiliados y desplazados del mundo. Desterrados de su tierra natal: lugar común de sus familias, sus ancestros y sus sentimientos. Arrancados de una tierra que, según Rocha (2012), retomando a Heidegger (1983), es “experimentada de manera especial en la nostalgia [...] es decir, precisamente en la ausencia y la lejanía del lugar de origen [...] que imposibilita la apropiación [...] de aquello que consideramos como propio" (p. 40).

Para Galeano (2006), los ninguneados son "los hijos de nadie, los dueños de nada [...], los ningunos [...] que no figuran en la historia universal, sino en la crónica roja de la prensa local, los nadies que cuestan menos que la bala que los mata" (p. 52). Cuerpos suprimidos, condenados a la miseria y la infelicidad, acorralados por la gran urbe, mancillados por la guerra y anulados por el individualismo patológico de las sociedades modernas. Los nadies van por el mundo viviendo-muriendo sus vidas anónimas, velados de invisibilidad aun cuando no son invisibles, llenos de escasez, sin poder negarse o quejarse. La civilización basada en el consumo así lo demanda. Para Galeano, el nadie, "ha nacido para morir de hambre" (2004, p. 19), para que viva "el que ha nacido para morir de indigestión" (p.19). Porque, el "alimento de las minorías se convierte en el hambre de las mayorías" (Galeano, 1994, p. 70). Condición del ninguneado, que no es una invención exclusiva de estos tiempos contemporáneos. En la antigua Grecia, hace más de 2500 años, Glaucón, hermano de Platón, contó a Sócrates la historia de un pastor del reino de Lidia, que algún día encontró un anillo mágico, y al ponérselo el pastor se hacía invisible y nadie podía verlo. “Glaucón y Sócrates filosofaron largamente sobre las derivaciones éticas de esta historia, pero ninguno de los dos se preguntó por qué las mujeres y los esclavos eran invisibles en Grecia, aunque no usaban anillos mágicos" (Galeano, 2012, p. 202).

En América, tras la llegada de los europeos, surgen miríadas de seres humanos de condición ninguneada: en esclavos fueron convertidos sus habitantes originarios. Indígenas obligados al trabajo forzado en las minas de plata durante la época colonial. Escenas apocalípticas de "la extenuación y el hambre de la multitud de indios que arrancaban plata a las tripas del Cerro Rico de Potosí" (Galeano, 2008, p. 130). Mejor suerte no corrieron los millones de africanos esclavizados, que fueron arrojados como mercancía en las playas americanas por las embarcaciones del viejo mundo. "Europa había tenido la gentileza de civilizar el África negra, [...] le había arrancado a sus hijos más fuertes y los había vendido en los mercados de esclavos" (Galeano, 2005, p. 60). Esta demostración inequívoca de barbarie "produjo diferentes silencios que volvieron impronunciables diversas necesidades y aspiraciones de pueblos o grupos sociales cuyas formas de conocimiento fueron aniquiladas" (Santos, 2006, p. 29). Americanos y africanos callados a látigo, sangre y fuego, por la mano del colonizador que los hizo invisibles, sin necesidad de que usaran "anillos mágicos".

Barbarie de la civilización occidental, expresión de su capacidad para reproducir la desigualdad, tanto o mejor de como reproduce los grandes capitales. Paradoja de los tiempos basados en la razón, padecida por los 
ninguneados. Mientras el racionalismo hace lo propio para el mantenimiento del orden criminal que gobierna al mundo, también convierte en objeto de estudio las estrechas condiciones de pobreza de los dueños de nada. Nadies, que para la ciencia oficial son solo objetos de estudio medibles, más que una preocupación verdadera. De los pobres, expertos y políticos lo saben todo: “en qué no trabajan, qué no comen, cuánto no pesan, cuánto no miden, qué no tienen (Galeano, 2012, p. 201). Sin embargo, aclara Galeano: "sólo nos falta saber por qué los pobres son pobres. ¿Será porque su desnudez nos viste y su hambre nos da de comer?" (p. 201). Su miseria, su dolor, su tristeza y su angustia no cuentan para las medidas insensibles; ellos son solo números. "Las estadísticas dicen que son muchos los pobres del mundo, pero los pobres del mundo son muchos más que los muchos que parecen que son" (Galeano, 2005, p. 83). Datos que mienten para salir en defensa del capitalismo manifiesto, pero "aunque sonrían las estadísticas, se jode la gente [...], cuando crece la economía también crece, con ella, la injusticia social" (Galeano, 2010, p. 359).

En este sistema organizado al revés, esmerado con afán en la inalcanzable satisfacción de la avaricia humana, los ninguneados están condenados a ser brazos baratos, manos tirables $^{2}$, simples recursos humanos sin derechos humanos, combustible de ganga para mantener en marcha las máquinas de hacer riqueza abusiva. Realidad de un mundo determinado por las formas maquínicas que lo controlan todo, donde los cuerpos son atropellados sin ningún escrúpulo por el egoísmo inseparable de un modelo consumista

2 Tirable, sinónimo de desechable, descartable, eliminable, suprimible. anclado en la injusticia y el exceso. Imposición del ritmo de las máquinas, fieles escuderas de este sistema, que devoran hombres y los expulsan mancillados. Las industrias manufacturan millones de seres ninguneados con una eficiencia envidiable y también hacen de sus cuerpos cosas. "La máquina, estéril, odia todo lo que crece y se mueve [...] No puede producir otra cosa que presos y cadáveres, espías y policías, mendigos y desterrados" (Galeano, 1983, p.70). Poder maquínico que expolia la naturaleza, multiplica el hambre y fabrica miedo, difunde la pobreza y concentra la riqueza. Las máquinas son preeminentes: "no exigen salario, ni vacaciones, ni aguinaldo, ni jubilación, ni indemnización por despido, ni nada más que la electricidad que las alimenta" (Galeano, 2004, p. 97).

\section{LOS NINGUNEADOS COMO CUERPOS DEL EXILIO: LA MORADA EXTRAVIADA}

Los ninguneados, como cuerpos del exilio, llevan una vida en la que se vive muriendo y se muere viviendo. No tienen más que obedecer a su trágico y urdido destino: el camino del éxodo obligatorio. Así es como "el mundo se parece ahora a cualquiera de las ciudades latinoamericanas: inmensos suburbios acorralan a las fortalezas amuralladas de los barrios de lujo" (Galeano, 1994, p. 25). Ciudades que abarcan más allá de la inmensidad visible, construidas de hormigón frío e insolidario, y donde los nadies, rechazados y desterrados, se vierten en la periferia. No por casualidad, en "las márgenes o las periferias, las estructuras de poder y de saber son más visibles" (Santos, 2006, p. 39). En estas ciudades se confunde ser con tener, y por eso los pobres allí no pueden ser más 
que cosas por fuera de los estrechos círculos de la opulencia. En los márgenes, reducto de las ciudades pensadas para las cosas y no para las personas, están los ninguneados. Como en la gran urbe argentina, revelada en la historia de Eva Duarte, quien "no es dueña de ninguna cosa [...], y ahora es una nadie entre los miles de nadie que los trenes vuelcan cada día sobre Buenos Aires [...] obreros y sirvientas que entran a la boca de la ciudad y son por ella devorados" (Galeano, 2015, p. 43).

“En las viviendas de lata, barro y madera que brotan antes de cada amanecer en los cinturones de las ciudades, se acumula la población marginal arrojada a las ciudades por la miseria y la esperanza"(Galeano, 2010, p. 321). Incómodos excedentes del sistema, que no tienen cabida en los deslumbrantes edificios de imposible acceso, con presencia en las semaforizadas avenidas solo como cuerpos mendicantes, lo mismo que en las grandes superficies comerciales donde las pantallas, titanes de led alucinante, promueven el consumo de mercancía prohibida para ellos. "La publicidad manda a consumir y la economía lo prohíbe [...] órdenes de consumo, obligatorias para todos pero imposibles para la mayoría" (Galeano, 2004 , p. 18). La periferia contrasta con toda demostración de abundancia y exclusión. En los cinturones de miseria de las capitales se vive en condiciones antagónicas al lujo y al confort. Quienes tienen vedado el paso al paraíso del consumo habitan viviendas que en nada se comparan con la ostentosa mansión.

La fragilidad de estas viviendas, es la delicada frontera entre la intemperie y el calor de sus adentros, dramáticamente sentida cuando arrecian fuerzas acuosas sobre la morada. Contra toda predicción, son viviendas que acogen, pues cada una"recoge en sus brazos a los cansados y a los rotos, que de ella han brotado, y se abre para darles refugio al fin del viaje" (Galeano, 1994, p.39). "Vista íntimamente, la vivienda más humilde ¿no es la más bella?"(Bachelard, 2012, p.13). A pesar de las penurias, se habitan con afecto estos lugares del exilio; reducidos rincones dejados a su paso por el avance del progreso, lugares no extrañados que abrigan al dueño de nada. Casas dispuestas una enseguida de la otra, arriba y abajo, subterráneas y en barrancos, que mediante figuras caprichosas, hileras, trazos y otras líneas no siempre rectas, forman redes y configuran tejidos que bordean y abrazan la ciudad, vistiendo desde afuera sus privacidades. Son el manto de la periferia, extensos paisajes que orillan la ciudad, alejados del poder y las élites, tupidos hasta donde la vista puede de tugurios ${ }^{3}$, chozas, covachas ${ }^{4}$, guaridas, cuchitriles ${ }^{5}$, tabucos ${ }^{6}$, antros, escondites y casas chonetas en "obra negra"y de bahareque, hechas con barro y palos entretejidos - la obra blanca es ausente- . En Bogotá se les llama comunas, invasiones y barrios marginales;" favelas en Río de Janeiro, callampas en Santiago de Chile, jacales en México, barrios en Caracas y barriadas en Lima, villas miseria en Buenos Aires y cantegriles en Montevideo"(Galeano, 2010, p. 322).

3 Con el nombre de tugurio se designa una habitación o una vivienda pequeña, mezquina y miserable (Real Academia Española, 2014).

4 Una covacha es una vivienda pobre, pequeña, oscura, sucia e incómoda (Real Academia Española, 2014).

5 Cuchitril es una palabra despectiva para referirse a una vivienda 0 habitación estrecha y sucia (Real Academia Española, 2014).

6 Un tabuco es un aposento pequeño, sucio y estrecho (Real Academia Española, 2014). 
Los expertos en pobreza llaman al fenómeno crecimiento urbano subnormal, pero esta es una mención indirecta y suavizada, un eufemismo para referirse al lugar de habitación de los cuerpos desobrados de la periferia. Eduardo Galeano (1994) insiste en que "el lenguaje oficial ahoga la realidad para otorgar impunidad a la sociedad de consumo" (p. 10). Crecimiento que agrupa casas diminutas y multiformes, construidas en las frágiles y empinadas laderas, en lugares desolados y vulnerables a las fuerzas de la tierra. Casas pequeñas y muy pobres - jurgoneras ${ }^{7}-$, donde viven oprimidos, apretados, exprimidos los que poco tienen, los ignorados de este mundo, los niguate$\operatorname{ros}^{8}$. En quechua, "huaico llaman los peruanos a la avalancha humana descargada desde la sierra sobre la capital en la costa" (Galeano, 2010, p.321). En lengua guaraní, una aproximación a la condición del ninguneado se escribe mboriahu, mboriahueterei'; en lengua aymara es tukusita, mayjasiri ${ }^{10}$; en quechua, waxcha ${ }^{11}$, y en esta misma, una forma despectiva de la casa de un ninguno es khuchiwasi ${ }^{12}$. En Colombia se les llama patirrajados ${ }^{13}$, gamines ${ }^{14} \mathrm{y}$ desechables. Mujeres,

7 En los departamentos colombianos de Cundinamarca y Santander, coloquialismo para nombrar una casa pequeña y muy pobre (Academia Colombiana de la Lengua, 2012).

8 Coloquialismo para referirse a una persona de mal comportamiento y poco importante (Academia Colombiana de la Lengua, 2012). En expresiones como: "Ese tipo es un pobre niguatero».

9 Pobre, miseria, menesteroso, proletario, paria, miserable.

10 Extinto, paupérrimo o muy pobre; mendigo.

11 Pobre, mendigo, huérfano, menesteroso.

12 Pocilga

13 Coloquialismo despectivo para nombrar o referirse a una persona de pocas posibilidades económicas y baja condición social (Academia Colombiana de la Lengua, 2012). En expresiones como: Aquel es un pobre patirrajado.

14 En Colombia y Venezuela, niño o joven que vive en la calle y pide limosna o roba. También coloquialismo despectivo para referirse a hombres y niños "abandonados de las calles de Bogotá, que antes se llamaban gamines, ahora se llaman desechables y están marcados para morir" (Galeano, 2004, p. 60). En Venezuela los llaman "toderos, porque hacen de todo: los marginados viven de 'changas', mordisqueando trabajos de a pedacitos y de cuando en cuando" (p. 321). Son maneras de nombrar a seres humanos obligados "a vivir al servicio de cualquier actividad ganapán, deslomándose a cambio de la comida, o de poco más, todo a lo largo y ancho del mapa del mundo"(p. 13).

\section{El desArROLlo: LA PROMESA DE SER COMO ELLOS}

Las ciudades de América Latina, tierra de "pocos propietarios, muchos poseídos [...] pocos consumidores, muchos consumidos" (Galeano, 1994, p. 24), son asoladas, según los expertos, por el subdesarrollo como castigo al mal comportamiento y la ineficiencia de sus habitantes. Sentencia de una tierra desaplicada, responsable de su propia desgracia. Los nadies, los ningunos, según los criterios económicos del libre mercado y los datos oficiales, son los culpables del amargo destino que gobierna sus vidas. La historia, que también ha sido ninguneada, así lo enseña por imposición de los vencedores: hombres de la historia occidental eurocéntrica con su propia versión de los hechos históricos. Sus relatos "nos han acostumbrado a olvidar lo que merece memoria y a recordar lo que merece olvido" (p. 27). El ninguneado está obligado a aceptar sumisamente la miseria, como un designio de la naturaleza y la providencia. “Si el destino está en los genes,

una persona brusca y tosca en su trabajo (Academia Colombiana de la Lengua, 2012). 
la riqueza de los ricos es inocente de cinco siglos de crimen y saqueo, y la pobreza de los pobres no es un resultado de la historia, sino una maldición de la biología" (p. 24). La única propiedad del nadie es una memoria extranjera, extraña e indiferente, que produce olvido y enseña a sobrellevar una realidad para no cambiarla.

Las crónicas mienten y no cuentan - por principio de conveniencia - que la condición de los ninguneados no se debe a su mala conducta, sino al orden mundial del que los países ricos son defensores, defendidos y abanderados. Pensamiento globalizante que origina a los nadies, no el supuesto desorden de los nacidos en América del Sur y otras periferias. "Los países ricos aprenden a ignorar. La historia oficial no les cuenta [...], el origen de su riqueza. Esa riqueza, que no es inocente, proviene en gran medida de la pobreza ajena" (Galeano, 1992, p. 12). Historia que no confiesa que poco después del arribo de los conquistadores América comenzó a financiar la sacra expansión imperial de Europa, con los minerales preciosos de sus entrañas y el sufrimiento de su pueblo. "El 12 de octubre de 1492 había nacido esta realidad que hoy vivimos a escala universal" (Galeano, 1994, p. 22). Se silencian las voces de la verdad histórica, para que no se sepa que "el subdesarrollo latinoamericano es una consecuencia del desarrollo ajeno [...] los latinoamericanos somos pobres porque es rico el suelo que pisamos [...] los lugares privilegiados por la naturaleza han sido malditos por la historia" (Galeano, 2010, p. 341). Lugares en los que la geografía americana es generosa; basta citar el Cerro Rico del Potosí en Bolivia, las regiones esmeralderas de Boyacá en Colombia y las antiguas minas del salitre en Chile.
Los dueños de nada no tienen derecho a una historia propia, ni hacen historia aunque la hacen. En su caso, la historia es un producto de importación que reciben sin posibilidad de rechazo, manufacturado en las lejanas metrópolis del poder, y que se difunde a través de los textos escolares, cuyas páginas ocultan las atrocidades y demuestran cómo "el colonialismo fue concebido como una misión civilizatoria" (Santos, 2006, p. 38). La invasión de los "caballeros españoles" es la prosa de una aventura épica alentada por las buenas intenciones que cruzaron el Atlántico en un acto generoso de salvación, trayendo la civilización a tierras supuestamente desconocidas. Estos "protagonistas de las aventuras coloniales han pasado a la historia como agentes viajeros de Dios. Era la civilización lanzada al rescate de la barbarie" (Galeano, 2008, p. 120). Lamentablemente, "poco o ningún espacio ocupan, en los textos que enseñan el pasado americano, las rebeliones indígenas, que fueron continuas desde 1493, y las rebeliones negras" (Galeano, 1992, p. 9). Cuando se enseña el "descubrimiento" de América, se omite una palabra que de otro modo resultaría reveladora: conquista, y en su lugar se habla de un encuentro de dos mundos. Las versiones oficiales no están dispuestas a confesar que el continente sí fue descubierto, pero para la ambición europea.

Menos aún, se escribe en dichas páginas que el continente ya había sido descubierto desde mucho antes por sus habitantes originarios. Siglos previos a la Colonia, coexistían en América maneras exuberantes y diversas de vivir, con lenguas, cosmovisiones, organizaciones políticas y económicas propias. Pero la apropiación de la tierra y el total irrespeto por parte del conquistador 
por todo lo que no entendía destruyeron todos estos saberes. Sin importar la crueldad de la que fueron víctimas, los pueblos originarios pasaron a la historia como deudores del favor de la dominación que redime del salvajismo. La situación no ha cambiado mucho desde entonces. "Contra las indios vivos continúan los desalojos, los saqueos y las matanzas. Y continúa el desprecio [...] los medios modernos [...] enseñan el autodesprecio [...] los niños indios juegan a los cowboys, y es raro encontrar quien quiera hacer el papel de indio" (Galeano, 1992, p. 13). Como lo menciona Santos (2006): “[...] el fin del colonialismo como una relación política, no trajo el fin del colonialismo en cuanto relación social, en cuanto mentalidad ni como forma de sociabilidad autoritaria y discriminatoria" (p. 39).

En un mundo enfermo por el dinero, la cuidadosa manipulación de la historia está bien justificada, pues asegura la continuidad de un orden mundial excluyente y adalid de la distribución desigual. Esta historia, que fomenta la mala memoria, diseñada para el olvido obligatorio e insospechable, no permite que América del Sur se reconozca a sí misma. "El dominio global [...] trajo consigo la destrucción de varias formas de conocimiento, particularmente aquellas propias de los pueblos sometidos bajo el colonialismo" (Santos, 2006, p. 29). La tierra de los habitantes originarios-americanos pasó a ser considerada un recurso dispuesto a la explotación exponencial. El sistema imperante ha hecho todo lo posible por abolir la primacía de la vida exuberante, para instaurar el culto a las cosas. Esta idea se vende como la panacea salvadora de los ninguneados. Desdén del desarrollo donde "las crías sobrantes humanas se eliminan por hambre o tiro. Los niños de la calle, los hijos de la mano de obra marginal, no son ni pueden ser útiles a la sociedad" (Galeano, 1994, p. 132). Mentira solapada del discurso del desarrollo, que augura el alivio a las penurias de los muchos que poco tienen, los dueños de nada. Pero, "el mundo los invita a desaparecer, les dice: 'ustedes no existen porque no merecen existir'” (Galeano, 2004, p. 61).

Los países del sur, tan ninguneados como la inmensa mayoría de sus millones de habitantes, están llamados a copiar forzosamente el ejemplo de los países ricos, a fin de ser como ellos. Es necesario un récord de buena conducta y obediencia intachable para alcanzar el anhelado Estado de desarrollo, para ser un desarrollado. "Un destino de prosperidad recompensará la buena conducta de los muertos de hambre" (Galeano, 1992, p. 115). No hay lugar ni tiempo para objeciones, cualquier muestra de resistencia se considera un acto de traición y mala conducta. Está prometido que si los dueños de nada se portan bien y acatan las órdenes del conquistador serán cultos, ricos y felices. Serán “todos iguales, sin distinción de raza, color, sexo, idioma, religión ni opinión [...] en un mundo que será maravilloso para todo lo que no tenga piernas ni patas ni alas ni raíces" (Galeano, 1994, p. 118). El modelo que gobierna al mundo promete la igualdad a todos, pero las diferencias entre desdichados y elegidos, pobres y ricos, norte y sur, son evidentes y demuestran lo contrario. El empobrecimiento desmedido no da tregua, cada vez son más los ningunos y la periferia crece de la mano de las buenas intenciones del desarrollo sin límites, pues “allí donde más opulenta es la opulencia, más miserable resulta, tierra de contradicciones, la miseria" (Galeano, 1994, p. 68). 
La pobreza de muchas regiones de América Latina y el mundo desmiente la promesa de ser como ellos, como los del primer mundo. El modelo moderno de producción industrial y desgarramiento del planeta lo hacen imposible e impensable. “El 6 por ciento más rico de la humanidad devora un tercio de toda la energía y un tercio de todos los recursos naturales que se consumen en el mundo" (Galeano, 1994, p. 117). Además, no son confiables las promesas de un sistema que en los albores del siglo xx pregonó la derrota de la pobreza, anunciando "con los nombres de Paz, Libertad y Progreso [...] que el recién nacido iba liberar al mundo de la [...] miseria y la guerra" (Galeano, 2004, p. 177). Hoy, millones de ninguneados - muchos más que a principios del siglo pasado-ya comprobaron que no fue así. Por esta razón, Galeano se pregunta: “Dónde se cobra el ingreso per Cápita? [...] Los numeritos tienen mejor suerte que las personas. ¿A cuántos les va bien cuando a la economía le va bien? ¿A cuántos desarrolla el desarrollo? (Galeano, 2000, p. 57). Mienten las promesas, mienten los ninguneadores dueños del poder que omite a los excluidos. Se "arroja a los marginados, por millares y millares, lejos de la vista" (Galeano, 2010, p.322). Confinados en la periferia, los nadies, habitantes de las ciudades ocultas, padecen el rigor de las promesas irrealizables.

\section{EL POSTDESARROLLO: UNA MIRADA DELIRANTE-DESEANTE}

La palabra de Galeano anuncia un tiempo por-venir; "el tiempo de mirarse hacia dentro y encontrar un punto de contacto con aquel mundo y tiempo perdido, derrochado, destruido por el ser humano y su codicia" (Kovacic, 2015, p.323). Motivo para considerar el postdesarrollo en cuanto forma de pensamiento y práctica distintos, donde el desarrollo deja de ser el principio central organizador de las sociedades modernas, para ceder este papel a la vida en plétora diversa. Cuestionamiento a la preminencia del crecimiento económico como único telos de la cultura occidental. A la vez, deconstrucción de la matriz cultural eurocéntrica que agencia al desarrollo y su historicidad, anclada en una visión geográfica todavía colonial (Escobar, 2012). En este sentido, el postdesarrollo es una alternativa al desarrollo convencionalmente concebido, pero sí y solo sí deviene en grados de tensión, en alerta y en distancia frente a la palabra que lo acompaña: desarrollo, que hábilmente sabe camuflarse y mutar entre las lógicas del mercado voraz y las promesas del desarrollo sostenible, de terribles consecuencias para toda forma de vida y cultura, dadas las maneras tecnomaquínicas de sometimiento que en él subyacen. "En todo caso, la situación de riesgo en que se encuentra el planeta es según Galeano la resultante de la evolución del capitalismo con su saga de desarrollo, explotación y muerte" (Kovacic, 2015 , p. 344). Porque, "el capitalismo [...] transfigura todo lo que toca. Existe el bosque para que el hacha lo derribe y el desierto para que lo atraviese el tren; el río vale la pena si contiene oro y la montaña si alberga carbón o hierro" (Galeano, 1994, p. 107).

Con sus maneras de decir, "Galeano pone de relieve un fuerte acento en la cuestión del respeto al medio ambiente y a la convivencia entre la naturaleza y los seres humanos (Kovacic, 2015, p. 344), y denuncia la realidad social de los ninguneados, a quienes el sistema -desarrollo-prometió felicidad, pero solo les ha traído desgracia. 
Cuando Eduardo Galeano se pregunta ¿cómo no enarbolar una defensa de la naturaleza? (Kovacic, 2015, p. 323), incluye un clamor de abrigo y solidaridad por los millones de cuerpos desobrados por el desarrollo económico al que la modernidad dio libertad plena. Así, el postdesarrollo es una inquietante posibilidad de resistir y desatarse del desarrollo basado en la premisa de la modernización, la explotación de la naturaleza como ser no vivo, los mercados, la exportación, el egoísmo y el bienestar individual. Vecindad con principios, cosmovisiones y prácticas relacionales, en vez de la concepción dualista que domina al mundo y que separa seres vivientes de no vivientes, lo humano de lo no humano, el individuo de lo comunitario (Escobar, 2012). Regreso a la vida en comunidades de destino, como "la más americana de las tradiciones, la más antigua y obstinada tradición de las Américas" (Galeano, 1992, p. 14). Esto es una minga por el postdesarrollo, como dice Escobar: "un diálogo inter-cultural alrededor de las condiciones que podrían devenir en un pluriverso de configuraciones socio-naturales" (p. 24).

\section{EL MIEDO: CONDENA OBLIGADA DE LOS NINGUNEADOS}

El miedo manda, se lanza con fiereza, depara un mundo de individualismo habitado por personas temerosas de sí y temerosas del otro. Sistema estructurado en la desunión, para el cual "el prójimo no es tu hermano ni tu amante. El prójimo es un competidor, un enemigo, un obstáculo a saltar o una cosa para usar" (Galeano, 2000, p. 58). El miedo decide y regula todos los destinos; de los dominados que temen a la cólera del poder que, a su vez, teme a la ira y al levantamiento de los dominados. El temor es el rasgo fatal de un mundo en guerra, como lucrativo negocio de la industria de la seguridad cuyo mercado es el miedo generalizado. A propósito de esta industria, Eduardo Galeano menciona: “¿Dónde se miden sus éxitos? En la bolsa [...] la cotización de sus acciones es el mejor noticiero de cada guerra" (Galeano, 2005, p. 121). Rasgo común de un orden mundial que adora las cosas y desprecia a las personas, impuesto por los caminos desolados de Metus encarnado. El mundo tiene miedo. Tienen miedo hombres y mujeres a la carencia de dinero, el mercado teme a la ausencia de ellas con dinero, y a las conciencias no comprables. Esta es la condición de la vida moderna, en la que "unos no duermen por la ansiedad de tener las cosas que no tienen, y otros no duermen por el pánico a perder las cosas que tienen" (Galeano, 2004, p. 10).

Por otro lado, el miedo y el poder van unidos en una macabra relación de vieja data. Ya en la antigua China un consejero real recomendaba a su emperador: "el poder sin miedo se desinfla como el pulmón sin aire. Si sólo se castiga a los culpables, sólo los culpables tienen miedo" (Galeano, 2005, p. 109). Triste paradoja, pues el primer sacrificado, ejemplo del avezado consejo, fue el dueño de tales palabras. $Y$ desde entonces el miedo garantiza la continuidad del poder y el sistema de injusticia que lo representa. El paso del tiempo ha demostrado que dicho consejo era cierto. El miedo asegura la buena conducta de los nadies, presos del temor y la necesidad, condenados a la conformidad, en nombre del derecho legítimo a la propiedad privada auspiciada por el bien individual de mayor valor que la vida. "Para que nadie se pase de la raya, el 
sistema multiplica las armas de guerra. Incapaz de combatir contra la pobreza, combate contra los pobres, mientras la cultura dominante, cultura militarizada, bendice la violencia del poder" (Galeano, 1992, p.118). Binomio mortal de miedo y poder, en el que "la burocracia del dolor tortura al servicio del poder que la necesita para perpetuarse [...] El poder confiesa, torturando, que come miedo" (Galeano, 2008, p. 96). Tenebrosa amalgama que se traduce en guerras firmadas como transacciones perversas; mecanismo que paradójicamente extermina la vida que dice proteger, que significa el éxodo de millones de ninguneados y que se vende como el medio para alcanzar el discurso gastado de la paz. Infamias bélicas que "violan la naturaleza, secuestran países, roban salarios y asesinan gentíos" (Galeano, 2008, p. 119). Carnaval de irrespeto por la tierra y por los cuerpos que conquista.

Todo huele a miedo, las ciudades y los campos, el hogar y el trabajo, el parque y la escuela. El pánico es como una cárcel sin barrotes que regula los actos y los pensamientos. Son muchos los presos del miedo; la desconfianza se convirtió en habilidad de la supervivencia: vive quien desconfía del otro. Todos son merecedores de votos de desconfianza, los votos de confianza no son deseables. El sistema enseña que el riesgo aguarda en la oscuridad, por eso los nadies son peligrosos y acechan; enemigos mortales que atacan desde la periferia, “agazapados en los suburbios miserables, mordiendo envidias, tragando rencores. Los pobres: los pelagatos, los muertos de las guerras, los presos de las cárceles, los brazos disponibles, los brazos desechables" (Galeano, 2008, p. 119). No casualmente, hace siglos, Platón advertía con palabra profética, el peligro representado por seres inferiores, los de abajo - esclavos - y la relevancia de regularlos: "tienen una inevitable tendencia a odiar a sus amos y sólo una constante vigilancia podrá impedir que nos asesinen a todos" (p. 56).

El miedo, contagioso, es una pandemia que se distribuye ágilmente a través de los medios de la sociedad moderna. En las clases del terror a todos y por todo, mediáticamente impartidas, el orden mundial enseña a temerle a la libertad, que se muestra como un atributo altamente peligroso, si está en manos de los ninguneados. Solo el sistema económico es digno de libertad: único con facultades para domesticarla y administrarla. No obstante, existe una exhortación generalizada a que todos sean libres, pero no se dice que solo se trata de un lujo disponible para aquellos que pueden pagarlo. "Lo único libre son los precios [...], libertad de precios, libertad de cambios: cuanto más libres andan los negocios, más presa está la gente" (Galeano, 1983, p. 81). Desde esta determinación, los nadies, los ningunos, los duenos de nada, tienen prohibida la libertad, que para ellos, de acuerdo con su vida en los sórdidos lugares de la periferia, es una palabra ninguneada; palabra muerta de tanto nombrarse inútilmente. Algunas preguntas son inevitables: "¿Es libre un hombre condenado a vivir persiguiendo el laburo ${ }^{15}$ y la comida? ¿Cuántos tienen el destino marcado en la frente desde el día en que se asoman al mundo y lloran por primera vez?" (Galeano, 1983, p. 60), ¿¿La riqueza conduce a la libertad o multiplica el miedo a la libertad?" (Galeano, 1992, p. 119). Difícilmente

15 Palabra coloquial usada en Argentina y Uruguay que representa la idea de trabajar; su significado original fue robar, debido a que nació en el argot carcelario. 
es posible la libertad en un mundo que, en cuanto moderno, es dominado por el miedo; tan solo se trata de otra promesa banal. Cuando suenan las "músicas del miedo, mucha es la gente que cambia de opinión en un instante" (Galeano, 2005, p. 111).

\section{OCLUSIÓN: DERECHO AL DELIRIO; RESISTENCIA DE LOS NINGUNOS}

Ante el desprecio por la vida, como telos de un orden global de exceso consumista e inequidad, que dispone al mundo en la perversa aridez del miedo y el poder, el delirio - delirium - es un síntoma de buena salud. Delirio-deseante del desviarse, separarse, salirse, fugarse de los designios del sistema omniabarcante que lo controla y lo explota todo. Porque delirar es oposición y resistencia a los discursos histórico-políticos que fomentan la guerra, autentican el derecho a la propiedad privada por encima de los privados de propiedad, que aniquilan culturas, pueblos y memorias, y que instauran el desarrollo voraz como la única salvación mundial posible. Al delirar, se construyen mundos de otro modo, solidarios y exuberantes, pues "de los miedos nacen los corajes; y de las dudas las certezas. Los sueños anuncian otra realidad posible y los delirios otra razón. Al fin y al cabo, somos lo que hacemos para cambiar lo que somos" (Galeano, 2000, p. 92). Si los ninguneados deliran, entonces sueñan, ríen, dicen sin temor, denuncian, recobran su memoria, advierten que su pobreza es un ejercicio del poder ajeno y, lo más importante, resisten para celebrar la vida como una compartición festiva, como un ejercicio solidario de vida en $\mathrm{Co}^{-}$ munidad de destino. El derecho al delirio es un hacer-decir-pensar como reclamo cabal e insobornable, que invoca y exige justicia; también, es un sendero, un camino de fugarse de las perseverantes y eficaces maneras del miedo y la pobreza. Derecho de alzarse en desacuerdo a las realidades e historias mentidas, difundidas como inalterables y cargadas de mensajes que obligan a la resignación. Señal de mala conducta ante la mirada sofocante de los dueños del poder, pero que es un deseo anhelante y una enseñanza milenaria de los pueblos ancestrales. “Voces del pasado americano muy pasado. Las antiguas voces [...], que todavía nos dicen que somos hijos de la tierra" (Galeano, 1994, p. 32). Palabras que anuncian y recuerdan una sentida geopoética de la vida, que sí es posible en el vivir juntos, comer juntos, soñar juntos liados a una tierra como lugar nutricio y no como despensa de recursos. Un entre-nos que Eduardo Galeano escribe hermosamente:

Aunque no podemos adivinar el tiempo que será, sí que tenemos, al menos, el derecho de imaginar el que queremos que sea [...] ¿Qué tal si deliramos, por un ratito? Vamos a clavar los ojos más allá de la infamia, para adivinar otro mundo posible: el aire estará limpio de todo veneno que no venga de los miedos humanos y de las humanas pasiones; $[\ldots]$ la gente trabajará para vivir, en lugar de vivir para trabajar [...] vivir por vivir nomás, como canta el pájaro sin saber que canta $\mathrm{y}$, como juega el niño sin saber que juega $[\ldots]$ los políticos no creerán que a los pobres les encanta comer promesas $[\ldots]$ el mundo ya no estará en guerra contra los pobres, sino contra la pobreza, y la industria militar no tendrá más 
remedio que declararse en quiebra [...] nadie morirá de hambre, porque nadie morirá de indigestión; los niños de la calle no serán tratados como si fueran basura, porque no habrá niños dela calle [...]; la justicia y la libertad, hermanas siamesas condenadas a vivir separadas, volverán ajuntarse, bien pegaditas, espalda contra espalda [...]; en Argentina, las locas de Plaza de Mayo serán un ejemplo de salud mental, porque ellas se negaron a olvidar en los tiempos de la amnesia obligatoria [...]; el sexto mandamiento ordenará festejar el cuerpo [...] Amarás a la naturaleza, de la que formas parte; serán reforestados los desiertos del mundo y los desiertos del alma; los desesperados serán esperados y los perdidos serán encontrados, porque ellos son los que se desesperaron de tanto esperar y los que se perdieron de tanto buscar; seremos compatriotas y contemporáneos de todos los que tengan voluntad de justicia y voluntad de belleza, hayan nacido donde hayan nacido y hayan vivido cuando hayan vivido, sin que importen ni un poquito las fronteras del mapa o del tiempo [...] (2004, pp. 191-194).

Cierre temporal para decir en cierta cintura desde los ninguneados de Eduardo Galeano, que es posible el levantamiento de mundos-otros donde la consigna articulante sea: la vida en respeto inalienable, y no el controla través del miedo, el dolor y la injusticia. Mundos donde los derechos humanos incluyen el derecho a soñar, derecho a delirar.

\section{ReFERENCIAS}

Academia Colombiana de la Lengua. (2012). Breve diccionario de colombianismos. Bogotá: Ministerio de Educación Nacional de Colombia.

Alessandri, A., Somarriva, M. y Vodanovic, A. (1998). Tratado de derecho civil. Partes preliminar y general. Tomo I. Santiago de Chile: Editorial Jurídica de Chile.

Apuleyo, P., Montaner, C. y \& Vargas, A. (1996). Manual del perfecto idiota latinoamericano. Barcelona: Plaza \& Janés.

Bachelard, G. (2012). La poética del espacio. México, D. F.: Fondo de Cultura Económica.

Bordelois, I. (2006). Etimología de las pasiones. Buenos Aires: Libros del Zorzal.

Escobar, A. (2012). Una minga para el postdesarrollo: lugar, medio ambiente y movimientos sociales en las transformaciones globales. Bogotá: Desde Abajo.

Galeano, E. (1983). Días y noches de amor y de guerra. México, D. F.: Ediciones Era.

Galeano, E. (1984). Apuntes para un auto-retrato. Caravelle. Cahiers du monde hispanique et luso-brésilien, 43(43), 153-155.

Galeano, E. (1992). Ser como ellos y otros artículos. Buenos Aires: Siglo XXI.

Galeano, E. (1994). Úselo y tírelo. El mundo del fin del milenio visto desde una ecología latinoamericana. Buenos Aires: Planeta.

Galeano, E. (2000). El libro de los abrazos. Madrid: Siglo XXI.

Galeano, E. (2004). Patas arriba: la escuela del mundo al revés. Buenos Aires: Siglo XXI.

Galeano, E. (2005). Bocas del tiempo. Santiago de Chile: Pehuén.

Galeano, E. (2006). El libro de los abrazos. Buenos Aires: Siglo XXI.

Galeano, E. (2008). Espejos: una historia casi universal. Buenos Aires: Siglo XXI. 
Galeano, E. (2010). Las venas abiertas de América Latina. Madrid: Siglo XXI.

Galeano, E. (2012). Los hijos de los días. Madrid: Siglo XXI.

Galeano, E. (2015). Mujeres. Buenos Aires: Siglo XXI.

Kovacic, F. (2015). Galeano. Apuntes para una biografía. Buenos Aires: Ediciones B.

Monlau, P. (1856). Diccionario etimológico de la lengua castellana: ensayo precedido de rudimentos de etimología. Madrid: Editorial Universidad de Harvard.

Navarrete, S. (18 de abril de 2015). Eduardo Galeano, un pensador del Sur Global. Diario El Espectador. Recuperado de http://www.elespectador.com/noticias/ infografia/eduardo-galeano-un-pensador-del-sur-global

López, F. (2008). Breve historia de la mitología griega. Madrid: Ediciones Nowtilus.

Real Academia Española (2014). Diccionario de la Lengua Española 23. edición. Madrid: Espasa.

Rocha, A. (2012). Tierra natal: entre agonía y afirmación de la diferencia. Revista de Filosofía, 37(1), 33-57.

Rojas, I. (2015). Astronomía elemental. Volumen II: astrofísica y astrobiología. Valparaíso: Editorial USM.
Santos, B. (2006). Conocer desde el Sur. Para una cultura política emancipatoria. Lima: Fondo Editorial de la Facultad de Ciencias Sociales de la Universidad Nacional Mayor de San marcos.

Segura, S. (2014). Lexicón etimológico y semántico del latín y de las voces actuales que proceden de raíces latinas o griegas [incompleto]. Bilbao: Publicaciones de la Universidad de Deusto.

Sechi, G., M. (2007). Diccionario Akal de mitología universal. Madrid: Akal.

Suárez, J. C. (2005). Iusnaturalismo, personalismo y filosofía de la liberación: una visión integradora. Sevilla: Mad.

Tornero, A. (2000). Las maneras del delirio: las poéticas de David Huertas y Francisco Hernández.México, D. F.: Editorial Universidad Autónoma de México.

Vargas Llosa, M. (14 de abril de 2015). Critica el legado de Galeano: asegura que exhibió a Latinoamérica como una caricatura. Diario Emol. Recuperado de http://www.emol.com/noticias/maga zine/2015/04/14/712617/vargas-llosacree-que-galeano-caricaturizo-america-latina.html 